\title{
Outcomes of definitive surgical repair for congenitally corrected transposition of the great arteries or double outlet right ventricle with discordant atrioventricular connections: Risk analyses in 189 patients
}

Toshiharu Shin'oka, MD, PhD, Hiromi Kurosawa, MD, PhD, Yasuharu Imai, MD, PhD, Mitsuru Aoki, MD, PhD, Masakuni Ishiyama, MD, PhD, Takahiko Sakamoto, MD, PhD, Shinka Miyamoto, MD, Kyoko Hobo, MD, and Yuki Ichihara, MD

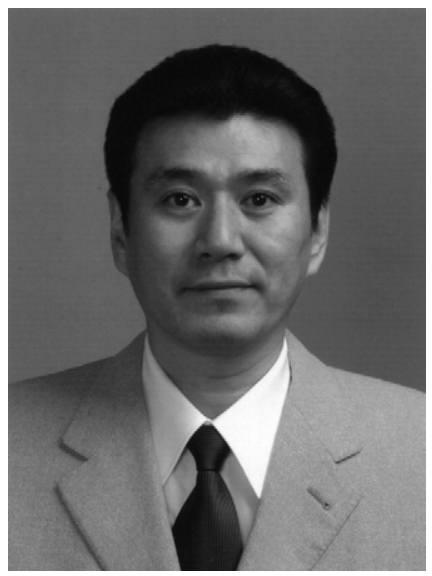

Dr Shin'oka

Supplemental material is available online.
From the Department of Cardiovascular Surgery, The Heart Institute of Japan, Tokyo Women's Medical University, Tokyo, Japan.

Read at the Eighty-sixth Annual Meeting of The American Association for Thoracic Surgery, Philadelphia, Pa, April 29-May 3, 2006

Received for publication July 25, 2006; revisions received Oct 25, 2006; accepted for publication Nov 3, 2006.

Address for reprints: Dr Toshiharu Shin'oka, Department of Cardiovascular Surgery, The Heart Institute of Japan, Tokyo Women's Medical University, 8-1 Kawada-cho, Shinjuku-ku, Tokyo 1628666, Japan (E-mail: ssinoka@hij.twmu. ac.jp).

J Thorac Cardiovasc Surg 2007;133:1318-28 $0022-5223 / \$ 32.00$

Copyright (๑) 2007 by The American Association for Thoracic Surgery

doi:10.1016/j.jtcvs.2006.11.063
Objective: This study was undertaken to compare long-term results of various types of surgical repairs for either congenitally corrected transposition of the great arteries or double outlet right ventricle with discordant atrioventricular connections, and to analyze the risk factors that affect early and late mortality and reintervention.

Methods: Between January 1972 and September 2005, a total of 189 patients (median age 8.3 years, range 2 months to 47 years old) with congenitally corrected transposition of the great arteries or double outlet right ventricle with discordant atrioventricular connections underwent definitive repairs. The definitive repairs comprised a conventional repair (atrial septal defect, or ventricular septal defect closure with or without pulmonary stenosis release, or isolated tricuspid valve surgery) in 36 patients (group I), conventional Rastelli in 31 patients (group II), double-switch operation (atrial switch plus arterial switch) in 15 patients (group III), atrial switch plus intraventricular rerouting (with or without extracardiac conduits) in 69 patients (group IV), and a Fontan-type repair in 38 patients (group V). The mean follow-up period was 10.1 years. Hospitalization and late mortality and reoperation were indicated as events. Risk factors for these events were analyzed by logistic regression for hospital death and a Cox proportional hazards model for late events.

Results: The Kaplan-Meier survival including hospital and late mortality was $62.4 \%$ at 32 years in group I, $78.5 \%$ at 27 years in group II, $74.5 \%$ at 15 years in group III, $80 \%$ at 16 years in group IV, and $79.3 \%$ at 22 years in group V. The reoperation-free ratio was $64.2 \%$ in group I, $76.6 \%$ in group II, $84.4 \%$ in group III, $89.6 \%$ in group IV, and $91.3 \%$ in group V. Risk analyses showed that the risk for hospital death was preoperative in patients with more than moderate tricuspid regurgitation and a cardiopulmonary bypass time of more than 240 minutes. A risk for late mortality was the presence of tricuspid regurgitation. Risks for reoperation were preoperative cardiomegaly, preoperative tricuspid regurgitation of more than grade II, ventricular septal defect enlargement, and body weight less than $10 \mathrm{~kg}$. Risks for pacemaker implantation, as indicated by multivariate analysis, were ventricular septal defect enlargement during operation and age less than 3 years.

Conclusions: There were no statistical differences between long-term survival rates of patients who underwent conventional surgical repair versus those of patients who underwent anatomic surgical repair. Results of conventional repair were satisfactory except in patients with significant tricuspid regurgitation. Results of anatomic repair were also satisfactory even for patients with significant tricuspid regurgitation, and therefore, anatomic repair should be the procedure of choice for those patients. 


$$
\begin{aligned}
& \text { Abbreviations and Acronyms } \\
& \begin{aligned}
\text { ASD } & =\text { atrial septal defect } \\
\text { AV } & =\text { atrioventricular } \\
\text { CTR } & =\text { cardiothoracic ratio } \\
\text { LD } & =\text { late mortality } \\
\text { PA } & =\text { pulmonary atresia } \\
\text { PM } & =\text { pacemaker } \\
\text { PS } & =\text { pulmonary stenosis } \\
\text { RA } & =\text { right atrium } \\
\text { RV } & =\text { right ventricular } \\
\text { TR } & =\text { tricuspid regurgitation } \\
\text { TVR } & =\text { valve replacement } \\
\text { VSD } & =\text { ventricular septal defect }
\end{aligned}
\end{aligned}
$$

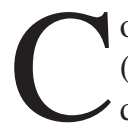

ongenitally corrected transposition of the great arteries (cc-TGA) or atrioventricular (AV) discordance with a double-outlet right ventricle (l-DORV) are characterized by AV and ventriculoarterial discordance. ${ }^{1}$ These two entities were thought to differ only in the grade of overriding of the posterior pulmonary artery. When both septums in the heart are intact, the circulation is physiologically normal, with no shunt, no pressure load, and no cyanosis. However, the anatomic right ventricle and tricuspid valve must sustain a systemic pressure. Before 1983, in our institute, conventional repair was the procedure of choice. However, we found that, after conventional repair, some of our patients developed a systemic right ventricular (RV) dysfunction or tricuspid regurgitation (TR) over the long term. Because of the disappointing results with conventional repairs, the first patient with cc-TGA underwent a Mustard-Rastelli procedure that resulted in early mortality in 1983. In 1989, a second patient successfully survived a double-switch operation (DSO). Since then, anatomic repair has become the procedure of choice in our institute (Figure E1). The purpose of this study was to compare long-term outcomes after conventional versus anatomic repair for cc-TGA/ 1-DORV. We also reviewed long-term results after a Fontan-type procedure for cc-TGA/ 1-DORV, although this comparison is only for reference because the biventricular repair was not feasible in this group. In addition, we had 6 patients with anatomically corrected malposition who underwent definitive correction using the anatomic left ventricle as a systemic ventricle without any mortality. These patients were excluded in this study because systemic ventricles are the anatomic left ventricles after corrective surgery without any switch procedures.

\section{Materials and Methods \\ Definitions of Terms}

Terms were defined as in Ilbawi's descriptions. ${ }^{2}$ Briefly, the terms "right ventricle" and "left ventricle" describe ventricular morphology rather than spatial orientation. "Tricuspid valve" refers to the AV valve associated with the anatomic right ventricle regardless of its location. Regarding the surgical procedure, "conventional repair" includes a conventional repair and conventional Rastelli procedure using the anatomic right ventricle as a systemic ventricle, and "anatomical repair" indicates a DSO or Senning/Mustard plus Rastelli procedure in which the anatomic left ventricle functions as a systemic ventricle.

\section{Patient Population and Data Acquisition}

One hundred eighty-nine patients with segmental anatomy [SLL] (n $=147)$ or $[\mathrm{IDD}](\mathrm{n}=42)$ who underwent definitive surgical repair at Tokyo Women's Medical University between January 1972 and September 2005 were identified from the database of the Departments of Cardiovascular Surgery and Pediatric Cardiology. Medical records, preoperative and postoperative echocardiograph data, and cardiac catheterization data and operative notes were reviewed. Long-term follow-up was obtained by review of patient records and outpatient clinic notes. Institutional Review Board approval was obtained prior to the initiation of these retrospective analyses.

\section{Diagnosis}

Patient diagnoses were categorized in the following 6 groups according to the associated cardiac lesions (Table 1).

1. Hemodynamically significant ventricular septal defect (VSD) alone

2. Hemodynamically significant VSD with pulmonary stenosis (PS)

3. Hemodynamically significant VSD with pulmonary atresia

4. Hemodynamically significant VSD with TR

5. TR alone

6. Others (including atrial septal defect [ASD] alone, PS alone, atrioventricular septal defect [AVSD], etc)

If both of the great arteries arose from the anatomic right ventricle for more than $150 \%$ or a truncal atresia of the pulmonary artery existed, a diagnosis of DORV was given. AV valve regurgitation was judged as none, I, II, III, and IV by Seller's classification. More than grade II regurgitation was defined as significant.

\section{Surgical Procedures}

The surgical procedures comprised a conventional repair (ASD or VSD closure \pm relief of PS, or isolated tricuspid valve surgery) in 36 patients (group I: conventional), conventional Rastelli in 31 patients (group II: conventional Rastelli), DSO (atrial switch plus arterial switch) in 15 patients (group III: DSO), atrial switch plus intraventricular rerouting ( \pm extracardiac conduits) in 69 patients (group IV: $\mathrm{M} / \mathrm{S}-$ Rastelli), and a Fontan-type repair in 38 patients (group V: Fontan).

Group I: Conventional Repair $(1972-2003 ; \mathbf{n}=36)$

Two patients had a complete form of AV septal defect; both defects were repaired by a conventional method, with 1 late death. Twelve of 36 patients required surgery for TR: valve replacement (TVR) in 8 patients and valve repairs in 4 patients. A mechanical valve was used in 6 patients, and a bioprosthetic valve was used in 2 patients. One patient with TVR had concomitant left ventricular (LV) assist device implantation with later heart transplantation. Three of 8 patients with TVR underwent PA banding for left ventricle training and failed. 
TABLE 1. Patient characteristics

\begin{tabular}{|c|c|c|c|c|c|c|c|}
\hline & & & gical procedu & & & & \\
\hline & Conventional & Conv. Rastelli & DSO & M/S-Rastelli & Fontan & Total & $P$ \\
\hline Number of patients & 36 & 31 & 15 & 69 & 38 & 189 & \\
\hline Age (y.) & $11.7 \pm 7.9$ & $13.8 \pm 8.3$ & $4.6 \pm 3.8$ & $7.4 \pm 4.2$ & $10.0 \pm 6.4$ & & \\
\hline Body weight (kg) & $29.0 \pm 16.7$ & $33.3 \pm 11.8$ & $14.7 \pm 8.0$ & $21.1 \pm 10.2$ & $28.3 \pm 16.9$ & & \\
\hline Max follow-up (y) & 32.8 & 27.8 & 15.4 & 15.4 & 22.5 & & \\
\hline Preoperative diagnosis & & & & & & & \\
\hline VSD & 5 & 0 & 14 & 0 & 0 & 19 & \\
\hline$V S D+P S$ & 15 & 18 & 1 & 22 & 27 & 83 & \\
\hline$V S D+P A$ & 0 & 13 & 0 & 46 & 10 & 69 & \\
\hline$V S D+T R$ & 4 & 0 & 0 & 0 & 0 & 4 & \\
\hline TR & 8 & 0 & 0 & 0 & 0 & 8 & \\
\hline Other & 4 & 0 & 0 & 1 & 1 & 6 & \\
\hline Cc-TGA & 33 & 13 & 13 & 13 & 20 & 92 & \\
\hline I-DORV & 1 & 18 & 2 & 56 & 15 & 92 & \\
\hline Other & 2 & 0 & 0 & 0 & 3 & 5 & \\
\hline Preoperative status & & & & & & & \\
\hline Previous surgery & 11 & 17 & 11 & 55 & 21 & 115 & \\
\hline Advance AV block & 3 & 1 & 0 & 2 & 1 & 7 & \\
\hline Significant TR (>II) & 15 & 3 & 10 & 5 & 9 & 42 & \\
\hline Preoperative hemodyna & & & & & & & \\
\hline CTR & $58.6 \pm 11.2$ & $49.2 \pm 7.5$ & $55.9 \pm 5.1$ & $50.3 \pm 5.6$ & $51.7 \pm 7.6$ & & $<.0001$ \\
\hline PA index & $505 \pm 248$ & $344 \pm 130$ & $365 \pm 113$ & $355 \pm 154$ & $418 \pm 128$ & & .0242 \\
\hline $\mathrm{PaO}_{2}$ & $66.6 \pm 16.8$ & $46.8 \pm 10.6$ & $70.1 \pm 15.1$ & $42 \pm 9.8$ & $42.2 \pm 6.5$ & & $<.0001$ \\
\hline Qp/Qs & $1.76 \pm 1.0$ & $0.83 \pm 0.4$ & $1.71 \pm 1.4$ & $1.1 \pm 0.56$ & $1.21 \pm 0.5$ & & $<.0001$ \\
\hline RAP & $7.8 \pm 2.7$ & $7.2 \pm 2.0$ & $7.7 \pm 3.4$ & $7.5 \pm 2.4$ & $7.8 \pm 2.5$ & & .8388 \\
\hline mean PAP & $26.1 \pm 18.4$ & $14.1 \pm 8.2$ & $26.3 \pm 13.4$ & $15.3 \pm 5.7$ & $14.7 \pm 2.5$ & & $<.0001$ \\
\hline RVEDV & $175 \pm 100$ & $108 \pm 32$ & $16 \pm 52$ & $121 \pm 38$ & $122 \pm 81$ & & .0012 \\
\hline RVEF & $0.54 \pm 0.10$ & $0.56 \pm 0.08$ & $0.51 \pm 0.11$ & $0.55 \pm 0.06$ & $0.52 \pm 0.06$ & & .2259 \\
\hline LVEDV & $201 \pm 24$ & $88.2 \pm 16$ & $191 \pm 71$ & $121 \pm 29$ & $115 \pm 54$ & & $<.0001$ \\
\hline LVEF & $0.54 \pm 0.14$ & $0.61 \pm 0.07$ & $0.60 \pm 0.07$ & $0.60 \pm 0.06$ & $0.61 \pm 0.06$ & & .0632 \\
\hline Intraoperative data & & & & & & & \\
\hline CPB time (min) & $139 \pm 54$ & $169 \pm 56$ & $235 \pm 44$ & $232 \pm 54$ & $154 \pm 59$ & & $<.0001$ \\
\hline Ao clamp time (min) & $65 \pm 41$ & $82 \pm 38$ & $104 \pm 30$ & $89 \pm 45$ & $49 \pm 51$ & & $<.0001$ \\
\hline
\end{tabular}

Conv. Rastelli, Conventional Rastelli; DSO, double-switch operation; M/S-Rastelli, Mustard/Senning-Rastelli procedure; VSD, ventricular septal defect; PS, pulmonary stenosis; $P A$, pulmonary artery; $T R$, tricuspid regurgitation; $c c-T G A$, congenitally corrected transposition of the great arteries; DORV, double outlet right ventricle; $A V$, atrioventricular; $C T R$, cardiothoracic ratio; $R A P$, right atrial pressure; $P A P$, pulmonary arterial pressure: $R V E D V$, right ventricular end-diastolic volume; $R V E F$, right ventricular ejection fraction; $L V E D V$, left ventricular end-diastolic volume; $L V E F$, left ventricular ejection fraction; $C P B$, cardiopulmonary bypass; $A o$, aorta.

The VSD was closed through the right atrium (RA) in 13 patients, through the right ventricle in 8 patients, through the aorta in 2 patients, and through the pulmonary artery (PA) in 1 patient. The PS was released in 15 patients without extracardiac conduits (patch LV outflow reconstruction in 2 patients, pulmonary valvotomy in 7 patients, and infundibular muscle resection in 6 patients). Two patients underwent debanding and pulmonary artery reconstruction. Two patients required surgical intervention to the anatomic mitral valve (annuloplasty in 1 patient and valve replacement in 1 patient).

\section{Group II: Conventional Rastelli Procedure (1977-2004; $\mathbf{n}=31)$}

In this group, the VSD was closed using DeLeval's technique in 27 patients. Transaortic approach was used in 4 patients. LV-PA conduits were placed between the LV apex and the central portion of the pulmonary artery. Dacron conduits with a bioprosthetic valve were used as extracardiac conduits in 25 patients, Dacron conduits with an autologous pericardial valve in 2 patients, nonvalved Dacron conduit in 1 patient, xenopericardial valved conduit in 1 patient, and a valveless polytetrafluoroethylene conduit in 2 patients. TR was found in 3 patients and was repaired by annuloplasty. Mitral regurgitation was also found in 3 patients and was repaired by annuloplasty.

\section{Group III: DSO $(1980-2000 ; n=15)$}

Of the 15 patients who underwent DSO, 14 had situs solitus and 13 had levocardia. As an atrial switch procedure, 12 patients underwent the Senning procedure and 3 had the Mustard procedure. All arterial switch procedures were performed using Lecompte's modification. The VSD was closed in 12 patients through RA. Seven of 15 patients had previous PA banding for LV training. Significant TR was found in 10 patients, and 5 of 10 patients underwent tricuspid annuloplasty. There were 2 patients who had significant mitral regurgitation. One 
underwent mitral annuloplasty, and the other underwent a concomitant mitral valve replacement. Three patients had significant supraventricular arrhythmia, and 2 patients underwent surgical cryoablation.

\section{Group IV: Senning or Mustard Plus Rastelli \\ Procedure (1983-2003; $n=69)$}

In this group, 46 of 69 patients had PA. Forty-eight patients had situs solitus, and 21 had situs inversus. Twenty-one Senning and 48 Mustard procedures were performed as atrial switch procedures, depending on the size of the RA. Concomitant extensive PA angioplasty for branch PA stenosis was needed in 22 of 69 patients. RV-PA reconstruction was done by RV-PA direct anastomosis plus valved patch in 19 patients, autologous pericardial conduit in 22 patients, and xenopericardial conduit in 28 patients. When the diameter of the VSD (primary interventricular foramen) was less than half of the aortic annulus, the VSD was enlarged $(n=33)$. Preoperative electrophysiologic studies indicated the position of the VSD enlargement. If the patients had an anterior AV node, the VSD was enlarged posteriorly. Significant TR was found in 5 patients, and mitral regurgitation was found in 5 patients. Mitral valve or annuloplasty was performed in 5 patients. One patient needed a concomitant aortic valve replacement. Eighteen patients experienced paroxysmal supraventricular tachyarrhythmia, 16 patients underwent surgical ablation, and 5 patients had catheter ablation before or after the operation.

\section{Group V: Fontan Procedure (1980-2004; $\mathbf{n}=38$ )}

Between 1980 and 2004, 38 patients with a diagnosis of cc-TGA or l-DORV underwent a Fontan procedure. Thirty-four patients underwent right atrial appendage-pulmonary artery anastomosis, and 4 patients underwent extracardiac total cavo-pulmonary connection with 4 hospital and 3 late deaths. Nine patients required tricuspid annuloplasty during the Fontan operation. No heart blocks occurred in this group.

\section{Postoperative Outcome}

Hospital mortality (HD) and late mortality (LD) and reoperation or reintervention were indicated as events. Pacemaker (PM) implantation was analyzed as a separate event from the reoperation. Risk factors for these events were analyzed by logistic regression for HD, and a Cox proportional hazards model was used for LD. Postoperative various hemodynamic data were compared among groups.

\section{Statistical Analysis}

Data were analyzed with statistical software (SPSS Windows 14.0, SPSS Inc, Chicago, Ill). The primary outcome variable was survival after the operation. Hospital death was defined as death in hospital after the operation, and late death was defined as death after discharge from the hospital. All death consisted of hospital death and late death. Reoperation events and pacemaker implantation events were also examined as outcome variables. Multiple clinical variables were analyzed for their possible effect on overall survival and event freedom by using the Cox proportional hazards model for categorical and continuous variables, in which cutoff points were also considered. Variables that were significant at the .1 levels in univariate analysis were included in a multivariate Cox proportional hazards model. A significant level of .05 was required for retention in the multivariate model. A logistic regression model was used for factorial analysis of hospital death. The KaplanMeier method was used to estimate probabilities of survival from all deaths and late deaths, as well as the probabilities of freedom from reoperation and PM implantation. Subgroups were compared with the use of the log-rank test. Patients lost to follow-up were excluded from analyses of survival and other outcomes.

\section{Results}

\section{General}

One hundred eighty-nine patients with the diagnosis of cc-TGA or 1-DORV who underwent surgery at the Heart Institute of Japan between January 1972 and September 2005 were examined. Between 1972 and 2005, 189 patients (58 women, 131 men) with cc-TGA or 1-DORV underwent definitive surgical repairs, either biventricular or univentricular. Associated lesions are summarized in Table 1. One hundred forty-seven patients had [SLL] segmental anatomy, and 42 patients had [IDD] segmental anatomy.

\section{Follow-up, Survival, and Events}

Patients were followed for a median of 9.8 years (range, 0.1-33 years). The mean follow-up period was 10.1 years. Considering both in-hospital and late events, the KaplanMeier survival rate including $\mathrm{HD}$ and LD was $62.4 \%$ at 32 years in group I, $78.5 \%$ at 27 years in group II, $74.5 \%$ at 15 years in group III, $80 \%$ at 16 years in group IV, and $79.3 \%$ at 22 years in group V (Figure 1, A). No statistical difference between the anatomic and conventional repair groups was observed (Figure 1, B). However, patients with a preoperative significant TR showed a statistically worse survival rate than did those of the other groups (Figure 2, A). In addition, patients with significant TR after conventional repair showed a statistically worse result than that of the other groups (Figure 2, 1B). The reoperation-free ratio was $64.2 \%$ in group I, $76.6 \%$ in group II, $84.4 \%$ in group III, $89.6 \%$ in group IV, and $91.3 \%$ in group V (Figure 3, A). There was no statistical difference between the anatomic and conventional repair groups in the reoperation incidence (Figure 3, B). The probability of PM implantation was higher in the anatomic repair group than that of the conventional repair group (Figure 3, D).

\section{Cause of Death and Late Events}

The cause of hospital and late deaths and reoperation are shown in Tables E1 and E2. The anatomic repair group tended to have fewer myocardial events but more arrhythmic events. Regarding the late reoperation events, the Fontan group showed the lowest incidence.

Univariate and Multivariate Analysis of Preoperative and Postoperative Variables That Affect Survival or Late Events (Appendices E1, E2, E3)

TR of more than degree II $(P=.003)$ and a cardiopulmonary bypass time of more than 240 minutes $(P=.02)$ were 

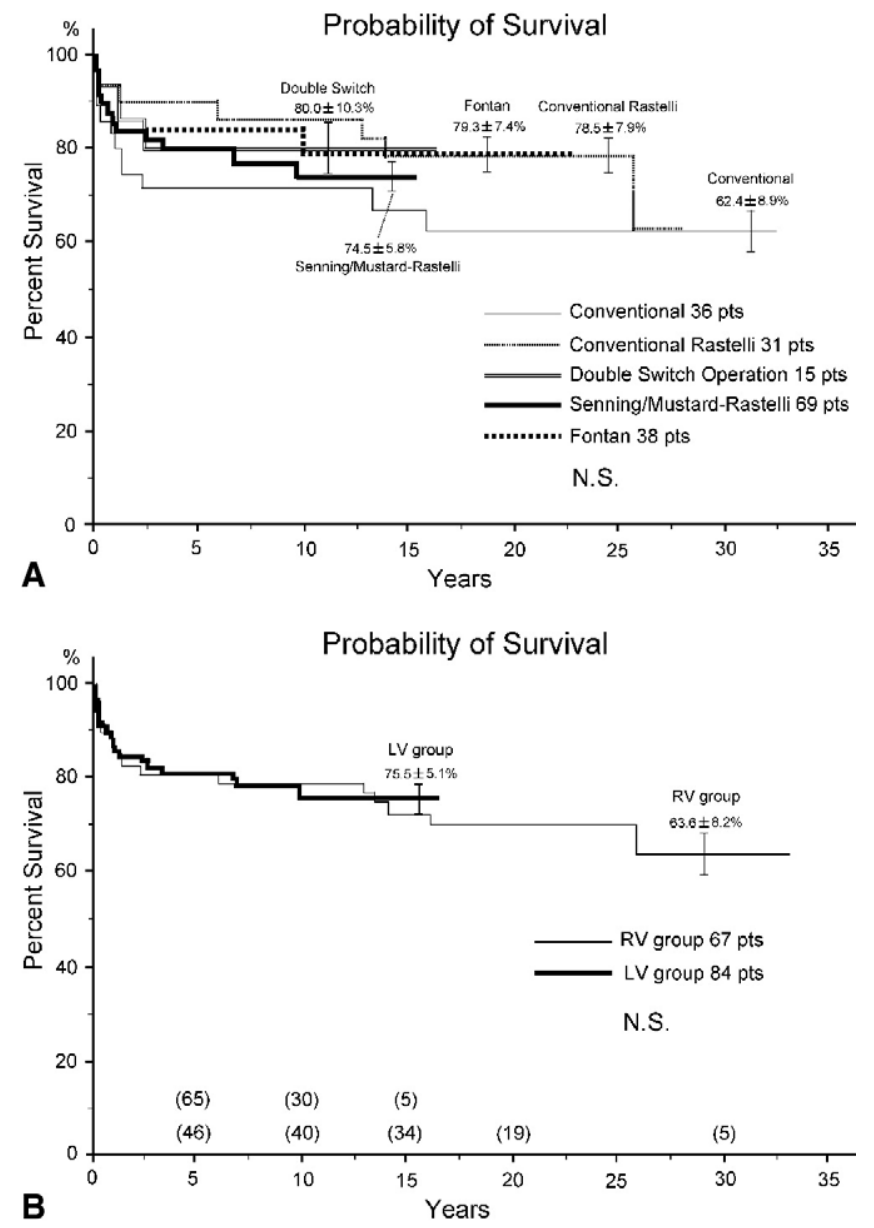

Figure 1. A, The probability of survival, in years, for the following operative groups: conventional repair (thin line, $n=36$ ), conventional Rastelli procedure (round dotted line, $n=31$ ), DSO (dotted line, $\mathbf{n}=15$ ), Senning/Mustard-Rastelli procedure (solid line, $\mathbf{n}=$ 69), Fontan pathway (dashed line, $n=38$ ). There was no statistical difference among the groups. B, The probability of survival, in years, for the following groups: RV group (right ventricle as a systemic ventricle; conventional + conventional Rastelli, $n=67$ ), LV group (left ventricle as a systemic ventricle; DSO + Senning/ Mustard-Rastelli, $n=84$ ). There was no statistical difference between the groups.

identified as risk factors for death at any time by means of univariate analysis. Risks for reoperation were preoperative cardiomegaly with cardiothoracic ratio (CTR) of more than $60 \%(P=.003)$, TR more than degree II $(P=.02)$, and body weight of less than $10 \mathrm{~kg}(P=.004)$ as indicated by univariate analysis. Risks for reoperation by means of multivariate analysis were preoperative cardiomegaly with CTR of more than 60\% $(P=.004)$ and VSD enlargement $(P=$ $.01)$. Risks for PM implantation were age less than 3 years old $(P=.001)$, preoperative existence of TR $(P=.01)$, Mustard/Senning + Rastelli procedure $(P=0.01)$, ana-
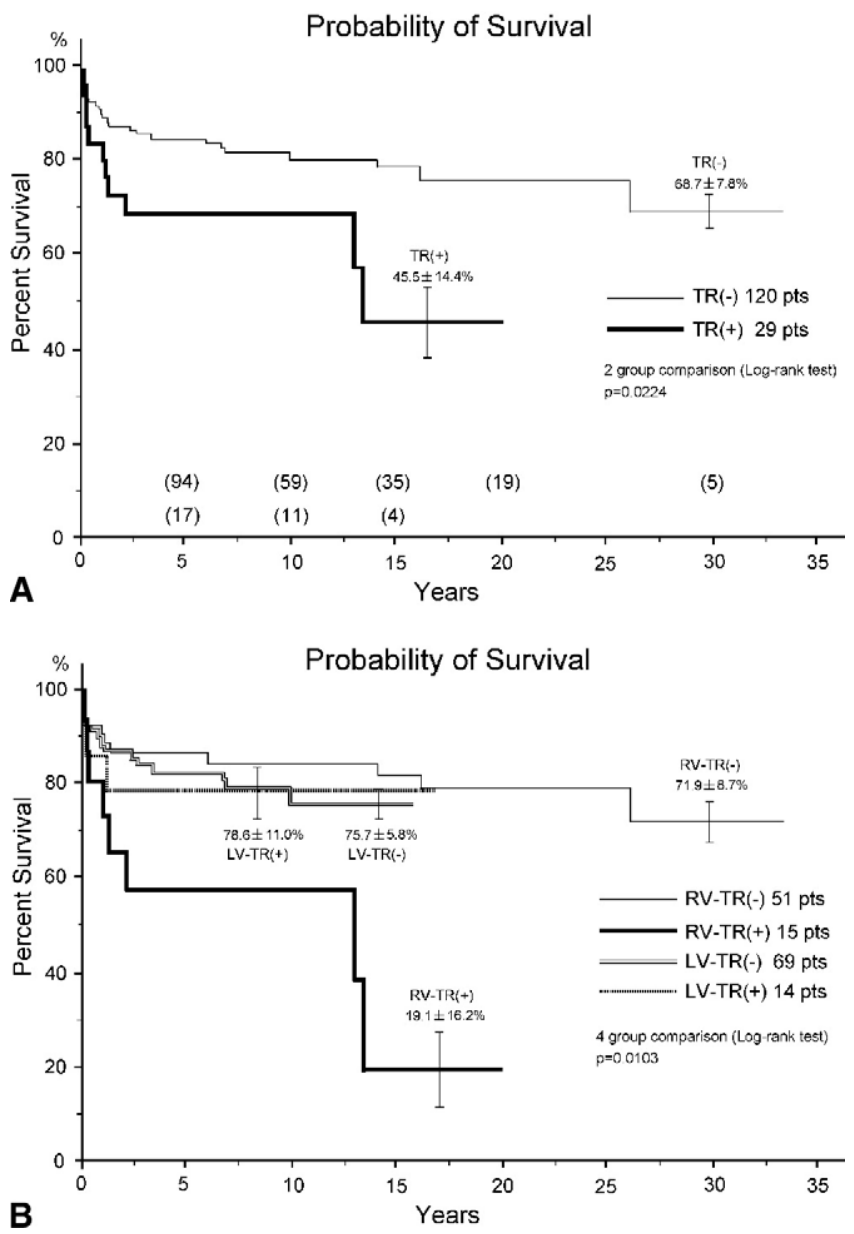

Figure 2. A, The probability of survival, in years, for the following operative groups: TR $(-)$ (thin line, $\mathrm{n}=120$ ) and TR $(+)$ (thick solid line, $\mathrm{n}=29$ ). $T R$, Tricuspid regurgitation. A statistical difference was observed between the groups (log-rank test, $P=$ .0224). B, The probability of survival, in years, for the following groups: RV-TR (-) group (right ventricle as a systemic ventricle; conventional + conventional Rastelli, $\mathbf{n}=51)$, RV-TR (+) group (right ventricle as a systemic ventricle; conventional + conventional Rastelli, $\mathbf{n}=15$ ), LV-TR $(-)$ group (left ventricle as a systemic ventricle; DSO + Senning/Mustard-Rastelli, $n=69$ ), LV-TR $(+)$ group (left ventricle as a systemic ventricle; DSO + Senning/Mustard-Rastelli, $n=14$ ). A statistical difference was observed among the groups (log-rank test, $P=.0103$ ).

tomic repair $(P=0.002)$, and VSD enlargement $(P<$ $.0001)$ by means of univariate analysis and an age of less than 3 years $(P=0.003)$ and VSD enlargement $(P=0.003)$ as indicated by multivariate analysis.

Analysis of Variance Among Groups in Postoperative Hemodynamic Data

Postoperative hemodynamic data were compared among groups. The results are shown in Table 2 . The postoperative 

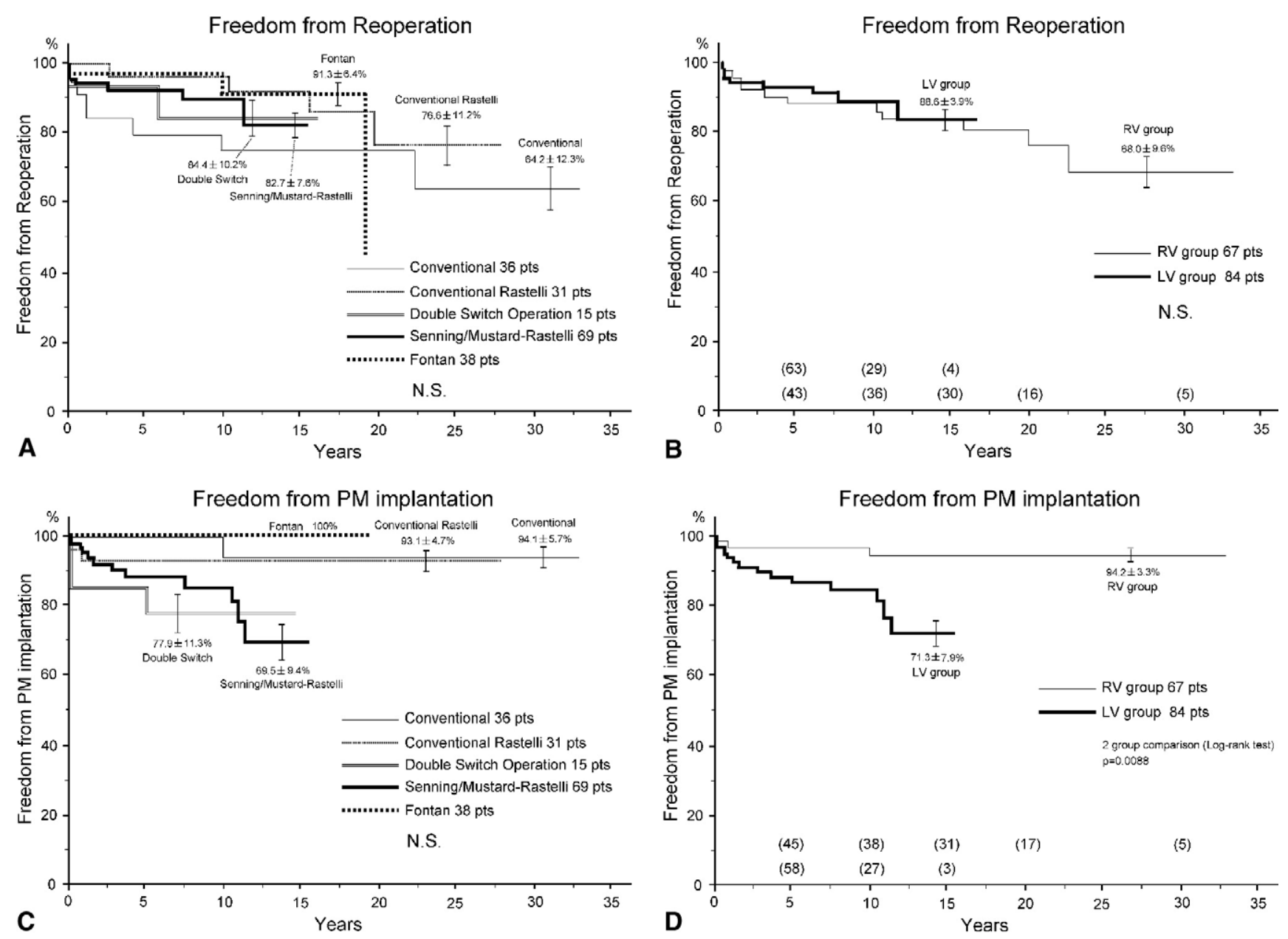

Figure 3. A, Freedom from reoperation for the following operative groups: conventional repair (thin line, $n=36$ ), conventional Rastelli procedure (round dotted line, $n=31$ ), DSO (dotted line, $n=15$ ), Senning/Mustard-Rastelli procedure (solid line, $n=69$ ), Fontan pathway (dashed line, $n=38$ ). No statistical difference was observed between the groups. B, Freedom from reoperation for the following operative groups: RV group (as a systemic ventricle; conventional + conventional Rastelli, $n=67$ ), LV group (left ventricle as a systemic ventricle; DSO + Senning/MustardRastelli, $\mathbf{n}=84$ ). No statistical difference was observed between the groups. C, Freedom from pacemaker implantation for the following operative groups: conventional repair (thin line, $n=36$ ), conventional Rastelli procedure (round dotted line, $\mathrm{n}=31$ ), DSO (dotted line, $\mathrm{n}=15$ ), Senning/Mustard-Rastelli procedure (solid line, $\mathrm{n}=69$ ), Fontan pathway (dashed line, $\mathbf{n}=38$ ). No statistical difference was observed between the groups. $D$, Freedom from pacemaker implantation for the following operative groups: RV group (right ventricle as a systemic ventricle; conventional + conventional Rastelli, $n=67$ ), LV group (left ventricle as a systemic ventricle; DSO + Senning/Mustard-Rastelli, $n=84$ ). A statistical difference was observed between the groups (log-rank test, $P=.0088)$.

systemic ventricular volume and ejection fraction were comparable between the conventional and anatomic repair groups. The Fontan group showed the lowest CTR and the least cardiac output index with the highest RA pressure.

\section{Limitations of This Study}

1. All data were obtained from a retrospective review in a single center, and results were retrospectively analyzed.
2. Each group contained patients of different preoperative status (statistically not equivalent by analysis of variance, such as preoperative CTR, PA size, $\mathrm{PaO}_{2}$, ratio of pulmonary/systemic flow, mean pulmonary arterial pressure, and ventricular volume in Table 1).

3. Each operation was performed during different chronologic time-periods; therefore, each has a different follow-up period. 
TABLE 2. Postoperative hemodynamic data

\begin{tabular}{|c|c|c|c|c|c|c|}
\hline & \multicolumn{5}{|c|}{ Surgical procedure } & \multirow{2}{*}{$\begin{array}{l}\text { ANOVA } \\
P \text { value }\end{array}$} \\
\hline & Conventional & Conv. Rastelli & DSO & M/S-Rastelli & Fontan & \\
\hline CTR & $54.9 \pm 9.7$ & $55.2 \pm 5.3$ & $50.6 \pm 6.0$ & $58.0 \pm 7.0$ & $49.7 \pm 8.9$ & $<.0001$ \\
\hline Cardiac index & $3.2 \pm 0.8$ & $3.3 \pm 0.9$ & $3.4 \pm 0.92$ & $3.2 \pm 0.7$ & $2.7 \pm 0.4$ & .0128 \\
\hline RAP & $5.0 \pm 1.2$ & $9.6 \pm 3.5$ & $9.1 \pm 3.6$ & $10.1 \pm 4.3$ & $13.7 \pm 2.8$ & .0006 \\
\hline RVEVP & $7.0 \pm 2.4$ & $11.8 \pm 3.4$ & $7.9 \pm 4.2$ & $10.2 \pm 4.8$ & N/A & .0211 \\
\hline LVEDP & $6.0 \pm 0.2$ & $11.6 \pm 2.8$ & $8.9 \pm 3.2$ & $11.7 \pm 3.7$ & N/A & .0001 \\
\hline RVEDV & $172 \pm 37$ & $120 \pm 45$ & $110 \pm 30$ & $122 \pm 52$ & $\mathrm{~N} / \mathrm{A}$ & .1173 \\
\hline RVEF & $0.47 \pm 0.11$ & $0.51 \pm 0.07$ & $0.55 \pm 0.1$ & $0.51 \pm 0.06$ & N/A & .2827 \\
\hline LVEDV & $102 \pm 30$ & $102 \pm 36$ & $174 \pm 55$ & $141 \pm 40$ & N/A & $<.0001$ \\
\hline LVEF & $0.68 \pm 0.06$ & $0.58 \pm 0.13$ & $0.51 \pm 0.05$ & $0.52 \pm 0.09$ & N/A & .017 \\
\hline
\end{tabular}

Conv. Rastelli, Conventional Rastelli; DSO, double-switch operation; M/S-Rastelli, Mustard/Senning-Rastelli procedure; RAP, right atrial pressure; EDP, end-diastolic pressure; RVEDV, right ventricular end-diastolic volume; $R V E F$, right ventricular ejection fraction; $L V E D V$, left ventricular end-diastolic volume; $L V E F$, left ventricular ejection fraction.

4. Each group had a small number of patients.

5. Patients with failed LV training were not included in this study.

6. Precise functional evaluation of both ventricles was not performed in this study.

\section{Discussion}

The long-term efficacy of the anatomic right ventricle as a systemic ventricle remains unknown in patients with discordant AV connections. A prevalence of systemic RV dysfunction and an abnormal response of the ejection fraction with exercise have been reported in patients with ccTGA or with an atrial switch repair for d-transposition of the great arteries (d-TGA). ${ }^{3-8}$ These patients are at risk of RV and TV dysfunction with increasing age, especially if Ebstein's malformation of TV is present. ${ }^{9,10}$ The optimal surgical management of patients with cc-TGA/l-DORV is still to be determined. Although several high-volume studies have reported long-term results after conventional surgical repair using the anatomic right ventricle as a systemic ventricle, ${ }^{11-13}$ no study has compared the long-term results between conventional and anatomic repair for cc-TGA/l-DORV.

The longest surgical follow-up series in cc-TGA was reported in 1999 by Yeh and colleagues, ${ }^{14}$ who described the outcome of 127 patients over a 40-year time period at the Hospital for Sick Children in Toronto, Canada. The rate of 20-year survival in their series was $48 \%$. In 2005, Hraska and colleagues ${ }^{12}$ analyzed 123 patients with cc-TGA. One hundred thirteen patients underwent intracardiac procedure, using either a traditional 2-ventricle repair $(\mathrm{n}=96)$ or Fontan procedure $(\mathrm{n}=17)$. They concluded that the poorest outcome was seen in patients who required tricuspid valve replacement either at the initial operation or later during follow-up; patients subjected to alternative approaches, such as Fontan, double-switch, or Senning-Rastelli procedure, may have better long-term results. The authors dem- onstrated a much better outcome in the Fontan patient group than the outcome of patients who underwent conventional surgical repair. However, the Fontan patients may have had lower cardiac output, and the follow-up periods described were relatively shorter than those of the other groups. In our experience, the survival rate after a Fontan procedure (RA appendage to PA anastomosis) seems to be satisfactory until 20 years after the operation. After 20 years, the survival curve dropped rapidly due to increased arrhythmia or heart failure. Therefore, we should be careful in using the Fontan procedure, even though the early results seemed to be good.

The concept of anatomic repair was introduced by Ilbawi and colleagues ${ }^{24}$ in 1990 and by Di Donato and associates in $1992^{15}$ as a combined atrial switch and Rastelli procedure. Combined arterial switch and atrial repair as an anatomic repair for cc-TGA was reported by Imai and coworkers in $1994 .{ }^{16}$ The first occasion of a DSO consisting of Senning and arterial switch operation was performed on a 2-year-old boy with cc-TGA associated with grade 3 TR on June 12, 1989, and a combined Mustard-Rastelli was successfully performed on May 25, 1990. ${ }^{17} \mathrm{Mee}^{18}$ stated that a Senning and arterial switch operation for cc-TGA was successfully performed in 1989. Imai and colleagues ${ }^{16}$ reported that early postoperative ventricular function after an anatomic repair was comparable to that of conventional repair and was even better in midterm results. The fact that the medium-term results indicated improved LV function and a favorable increase in cardiac output and LV ejection fraction with exercise suggests that temporary depression of the $\mathrm{LV}$ function in the immediate postoperative period may improve.

The outcome of patients with cc-TGA is variably affected by associated intracardiac defects, especially in the presence of tricuspid valve competence and systemic RV function. The importance of preoperative tricuspid valve regurgitation in conventional groups was reconfirmed in this study as in a previous study, ${ }^{12}$ although the mechanism of 
the TR was unknown and the incidence remains unpredictable. When patients do not have TR before their operation, the survival rate at 30 years after operation was about $72 \%$, even in the conventional repair group. This value is quite satisfactory, and the results of an anatomic repair were not superior to those after conventional repair in our series. We speculate that the reasons for this phenomenon are as follows:

1. LV function after anatomic repair deteriorated in approximately $15 \%$ to $20 \%$ of patients, and heart failure developed in the long-term period, as recently reported. ${ }^{18-20}$

2. In cc-TGA/l-DORV, the morphology of the mitral valve associated with the anatomic left ventricle is not exactly equivalent to that of the normal heart, and straddling of the mitral valve beyond the interventricular septum is often observed. Mitral valve anomalies in a heart with discordant AV connections exist in some percentage of patients.

3. In cc-TGA/l-DORV, the position of the anatomic left ventricle is different from that of the normal heart or a d-TGA heart, which may result in severe adhesion of the left ventricle to the sternum after surgery. This may cause LV dysfunction, because RV dysfunction was seen after a Senning procedure in d-TGA.

4. When a Senning-Rastelli procedure is selected in patients with a relatively small VSD, potential subaortic stenosis might influence the LV function in the late period.

5. The potential risk of supraventricular tachyarrhythmia may exist due to the atrial switch procedure.

Recently, several groups have reported excellent early results after the double-switch procedure, bringing this procedure into the mainstream. ${ }^{21-23}$ However, additional longterm data are needed, and early enthusiasm must be tempered with objective evidence. Our study failed to demonstrate the superiority of anatomic repair compared with conventional repair when the patient had no TR before operation.

In our series, 35 Senning and 49 Mustard procedures were selected as atrial switch procedures, depending on the size of the RA. Recently, we suggested that the Senning procedure is feasible in all atrial switch procedures, applying a large pericardial patch to augment a new functional left atrium, as others have described. ${ }^{18,24,25}$ No difference was observed between the Senning and Mustard groups in long-term results (data not shown).

Conduction abnormalities are common in discordant AV connections, predisposing the patients to the development of complete heart block. ${ }^{26,27}$ The incidence of heart block was higher in the anatomic group, which was related to the fact that VSD enlargement was aggressively performed to relieve a potential subaortic stenosis in our series. The VSD enlargement was a risk factor for complete heart block/PM implantation, although it was not a risk factor for hospital and late death.

There is general agreement among authors concerning the anterior conduction system in the situs solitus group, ${ }^{28}$ whereas the posterior conduction system was reported in cc-TGA in situs inversus. ${ }^{29}$ However, we had several patients with an anterior conduction system in IDD hearts (16 of 21 patients examined) and also a dominant posterior conduction system even in an SLL heart (5 of 48 patients examined). Furthermore, a sling of conduction bundle was reported in cc-TGA in situs solitus with a straddling mitral valve. ${ }^{30}$ Therefore, the direction of the VSD enlargement should be carefully determined by means of preoperative electrophysiologic examination, which usually diagnoses the site and dominance of the AV node, in our experience.

In conclusion, no differences were observed between long-term survival rates of patients who underwent conventional versus anatomic surgical repair. Results of conventional repair were satisfactory except in patients with significant TR. Results of anatomic repairs were also satisfactory even in patients with significant TR, and therefore, it should be the procedure of choice for those patients.

\section{References}

1. Van Praagh R. What is congenitally corrected transposition? N Engl J Med. 1970;282:1097-8.

2. Ilbawi MN, Ocampo CB, Allen BS, Barth MJ, Roberson DA, Chiemmongkoltip $\mathrm{P}$, et al. Intermediate results of the anatomic repair for congenitally corrected transposition. Ann Thorac Surg. 2002;73:594-9; discussion 599-600.

3. Graham TP Jr, Parrish MD, Boucek RJ Jr, Boerth RC, Breitweser JA, Thompson S, et al. Assessment of ventricular size and function in congenitally corrected transposition of the great arteries. Am J Cardiol. 1983;51:244-51.

4. Graham TP Jr, Atwood GF, Boucek RJ, Beoerth RC, Bender HW Jr. Abnormality of right ventricular function following Mustard's operation for transposition of the great arteries. Circulation. 1975;52:678-84.

5. McGrath LB, Kirklin JW, Blackstone EH, Pacifico AD, Kirklin JK, Bargeron LM. Death and other events after cardiac repair in discordant atrioventricular connection. J Thorac Cardiovasc Surg. 1985;90: $711-28$.

6. Lundstrom U, Bull C, Wyse RK, Somerville J. The natural and "unnatural" history of congenitally corrected transposition. Am J Cardiol. 1990;65:1222-9.

7. Graham TP Jr, Bernard YD, Mellen BG, Celermajer D, Baumgartner $\mathrm{H}$, Cetta F, et al. Long-term outcome in congenitally corrected transposition of the great arteries: a multi-institutional study. J Am Coll Cardiol. 2000;36:255-61.

8. Termignon JL, Leca F, Vouhe PR, Vernant F, Bical OM, Lecompte Y, et al. "Classic" repair of congenitally corrected transposition and ventricular septal defect. Ann Thorac Surg. 1996;62:199-206.

9. Imamura M, Drummond-Webb JJ, Murphy DJ Jr, Prieto LR, Latson LA, Flamm SD, et al. Results of the double switch operation in the current era. Ann Thorac Surg. 2000;70:100-5.

10. Voskuil M, Hazekamp MG, Kroft LJ, Lubbers WJ, Ottenkamp J, van der Wall EE, et al. Postsurgical course of patients with congenitally corrected transposition of the great arteries. Am J Cardiol. 1999;83:558-62.

11. van Son JA, Danielson GK, Huhta JC, Warnes CA, Edwards WD, Schaff HV, et al. Late results of systemic atrioventricular valve replacement in corrected transposition. J Thorac Cardiovasc Surg. 1995; 109:642-52; discussion 652-3. 
12. Hraska V, Duncan BW, Mayer JE Jr, Freed M, del Nido PJ, Jonas RA. Long-term outcome of surgically treated patients with corrected transposition of the great arteries. J Thorac Cardiovasc Surg. 2005;129:182-91.

13. Sano T, Riesenfeld T, Karl TR, Wilkinson JL. Intermediate-term outcome after intracardiac repair of associated cardiac defects in patients with atrioventricular and ventriculoarterial discordance. Circulation. 1995;92(9 suppl):II272-8.

14. Yeh T Jr, Connelly MS, Coles JG, Webb GD, McLaughlin PR, Freedom RM, et al. Atrioventricular discordance: results of repair in 127 patients. J Thorac Cardiovasc Surg. 1999;117:1190-203.

15. Di Donato RM, Troconis CJ, Marino B, Carotti A, Iorio FS, Rossi E, et al. Combined mustard and Rastelli operations. An alternative approach for repair of associated anomalies in congenitally corrected transposition in situs inversus [I,D,D]. J Thorac Cardiovasc Surg. 1992;104:1246-8.

16. Imai Y, Sawatari K, Hoshino S, Ishihara K, Nakazawa M, Momma K. Ventricular function after anatomic repair in patients with atrioventricular discordance. J Thorac Cardiovasc Surg. 1994;107:1272-83.

17. Imai Y. Double-switch operation for congenitally corrected transposition. Adv Card Surg. 1997;9:65-86.

18. Mee RB. The double switch operation with accent on the Senning component. Semin Thorac Cardiovasc Surg Pediatr Card Surg Annu. 2005; 17:57-65.

19. Bautista-Hernandez V, Marx GR, Gauvreau K, Mayer JE Jr, del Nido PJ. Determinants of left ventricular dysfunction after anatomic repair of congenitally corrected transposition of the great arteries [abstract]. 42nd annual meeting of the Society of Thoracic Surgeons 2006: p 78

20. Brawn WJ. The double switch for atrioventricular discordance. Semin Thorac Cardiovasc Surg Pediatr Card Surg Ann. 2005;8:51-6.

21. Langley SM, Winlaw DS, Stumper O, Dhillon R, De Giovanni JV, Wright JG, et al. Midterm results after restoration of the morphologically left ventricle to the systemic circulation in patients with congenitally corrected transposition of the great arteries. $J$ Thorac Cardiovasc Surg. 2003;125:1229-41.

22. Duncan BW, Mee RB, Mesia CI, Qureshi A, Rosenthal GL, Seshadri $\mathrm{SG}$, et al. Results of the double switch operation for congenitally corrected transposition of the great arteries. Eur J Cardiothorac Surg. 2003;24:11-9; discussion 19-20.

23. Devaney EJ, Charpie JR, Ohye RG, Bove EL. Combined arterial switch and Senning operation for congenitally corrected transposition of the great arteries: patient selection and intermediate results. $J$ Thorac Cardiovasc Surg. 2003;125:500-7.

24. Brawn WJ, Barron DJ. Technical aspects of the Rastelli and atrial switch procedure for congenitally corrected transposition of the great arteries with ventricular septal defect and pulmonary stenosis or atresia: results of therapy. Semin Thorac Cardiovasc Surg Pediatr Card Surg Апnи. 2003;6:4-8.

25. Devaney EJ, Ohye RG, Bove EL. Technical aspects of the combined arterial switch and Senning operation for congenitally corrected transposition of the great arteries. Semin Thorac Cardiovasc Surg Pediatr Card Surg Апnи. 2003;6:9-15.

26. Anderson RH. The conduction tissues in congenitally corrected transposition. Ann Thorac Surg. 2004;77:1881-2.

27. Hosseinpour AR, McCarthy KP, Griselli M, Sethia B, Ho SY. Congenitally corrected transposition: size of the pulmonary trunk and septal malalignment. Ann Thorac Surg. 2004;77:2163-6.

28. Anderson RH, Becker AE, Arnold R, Wilkinson JL. The conducting tissues in congenitally corrected transposition. Circulation. 1974;50: 911-23.

29. Thiene G, Nava A, Rossi L. The conduction system in corrected transposition with situs inversus. Eur J Cardiol. 1977;6:57-70.

30. Kurosawa H, Imai Y, Becker AE. Congenitally corrected transposition with normally positioned atria, straddling mitral valve, and isolated posterior atrioventricular node bundle. J Thorac Cardiovasc Surg. 1990;99:312-3.

\section{Discussion}

Dr W. Williams (Toronto, Ontario, Canada). Mr. Chairman, I have no conflicts of interest to disclose.
I would like to congratulate Dr Shin'oka and his colleagues for their report of their excellent, very large clinical experience in surgical management of patients with AV discordance. Their analysis focuses on survival and the factors that affect survival. Specifically, they address the important question of whether these patients are better served by an anatomic repair wherein the left ventricle is connected to the systemic circulation, rather than conventional repair in which the morphologic right ventricle remains the systemic ventricle. It's generally accepted that the right ventricle and its tricuspid valve are poorly suited to support the systemic circulation lifelong. There are, however, rare cases of isolated AV discordance in patients who have no associated lesions and who survive into the seventh and eighth decade of life, perhaps the exceptions that prove that rule.

The majority of patients with AV discordance have major associated lesions. The most prevalent are VSD, PS, or PA, TR, and AV block.

These 4 lesions occur in permutations and combinations, but, of course, any cardiac lesion may occur with AV discordance including single ventricle. In Dr Shin'oka's series, $21 \%$ of their patients had a Fontan operation for single ventricle.

In 1990, Dr Ilbawi reported success with anatomic repair for $\mathrm{AV}$ discordance as an alternative to conventional repair. Ilbawi's contribution of using the left ventricle in the systemic circulation expanded the options for these patients. There are now at least 8 surgical options to manage patients with AV discordance. Whether the more complex anatomic repairs will produce better long-term results remain unknown. I must say I am concerned about combining, in one patient, the well-known late complications of an atrial repair, whether a Mustard or a Senning, and those of the Rastelli-type repair.

Because there are so many surgical options and AV discordance is a rare lesion in which there are 4 commonly associated lesions that occur in various combinations, it is not surprising that the Tokyo series failed to demonstrate a difference in long-term outcome whether the left ventricle or the right ventricle was connected to the systemic circulation.

Indeed, the survival of their single-ventricle Fontan patients was identical to that of either anatomic or conventional repair.

Dr Shin'oka is not alone in failing to demonstrate a difference in survival for these various surgical approaches. My colleagues, Dr Brian McCrindle and Dr Glen Van Arsdell, recently published a meta-analysis of AV discordance in which they reviewed more than 60 papers. Their conclusion is worth repeating: "it will require a well designed, large, multicenter cohort study as the only practical solution in resolving the optimal choice of surgical procedures for these patients."

I have two questions for Dr Shin'oka. Number one, in the manuscript and in the bar graph that you showed, conventional repair was used during the most recent era in about $30 \%$ of the patients. Does this recent experience suggest a trend toward return to conventional repair? What are your current indications for conventional repair?

Dr T. Shin'oka (Tokyo, Japan). Thank you, Dr Williams, for your thoughtful comments and question. As you stated in your comments, I do agree that we need a large multicenter study to determine the optimal choice of surgical procedure for this rare entity using a more sensitive end point. 
In response to the first question, after 2000, we have demonstrated a trend toward a return to conventional repair when a patient has a relatively small-sized VSD and requires the VSD enlargement with a Rastelli procedure. In addition, VSD enlargement was a risk factor for the PM implantation, although VSD enlargement was not a risk factor for HD or LD.

Dr Williams. My second question is, what are your current indications for preparation of the left ventricle by pulmonary artery banding? In the series you reported today, 7 of the 15 patients had a PA band prior to a DSO. Other patients had PA bands but did not undergo anatomic repair. Given your considerable experience, which patients would you currently select for a PA band and in whom would you not attempt a PA band for preparation of the left ventricle?

Dr Shin'oka. This question concerns the indication of pulmonary artery banding for RV training. In our series, 7 of 15 patients underwent pulmonary artery banding prior to the arterial switch operation. The other 8 nonbanded patients had high LV pressure due to the VSD or subpulmonary stenosis; therefore, we did not have to do the banding before the switch operation. Also, 4 of the 7 banded patients had VSD, and 3 of the 7 banded patients had an intact ventricular septum. These 3 patients with an intact ventricular septum required LV training before the arterial switch operation. They also had very severe TR and RV failure before PA banding. In our country, heart transplantation is very limited. Therefore, in such a case, we attempt a PA banding procedure when the patient's family elects not to have direct tricuspid valve surgery after we explained the results of our past series.

Actually, selecting the best procedure is difficult in these patients with an intact ventricle septum and severe TR.

Dr C. Tchervenkov (Montreal, Quebec, Canada). I'd like to ask the question, as the long-term survival doesn't appear to be different between these various options, then we ought to look for additional benefits that the patient may have from these more complex anatomic repair procedures. Do you have any data on the functional assessment and status of these patient in terms of quality of life, exercise tolerance, et cetera, to help us elucidate which is the best option?

Dr Shin'oka. I agree with you. As Dr Williams pointed out, we need a large multicenter study to determine the optimal choice of surgical procedure for this rare entity using a more sensitive end point. We are currently analyzing the precise function of the anatomic left ventricle or right ventricle in a long-term period. We may be able to present this precise data at the next meeting.

Dr G. Van Arsdell (Toronto, Ontario, Canada). I would just add to that. It would be helpful to see $\mathrm{VO}_{2}$ data on these patients to understand whether or not we are achieving functional improvement. You have a significant cohort on whom you could perform that study.

In the meta-analysis we published last month, we noted that in the more recent era there was actually early survival benefit to doing an anatomic-type Rastelli-Mustard repair as opposed to a physiologic repair. That may be because of 2 reasons: 1 , when you do a physiologic repair, TR may be an immediate consequence; and 2, there is an immediate demand for the morphologic right ventricle to carry the systemic load without the benefit of a morphologic LV assist (closed VSD).
Your survival data appear to demonstrate this phenomenon. It's true at later follow-up the Rastelli-type repair and the physiologic repair appeared to be the same, but early outcome at 1 to 2 years seemed to be different. Did you divide your time of follow-up in outcomes to see whether or not there was a difference?

Dr Shin'oka. Thank you, Dr Arsdell, for your careful observation of our survival curve. We did not perform such an analysis, but that analysis may be useful for the further evaluation.

Dr Van Arsdell. The second question I had, I was interested in the fact that you would accept a VSD 50\% of the size of the aorta before you would enlarge it. But there have been some data to suggest that VSD enlargement impairs ventricular function, and we've actually felt that if you need to enlarge the VSD, perhaps we should do a more conventional-type repair. Were you able to follow the ventricular function on those patients who had a VSD enlargement and was it a predictor of poor ventricular function or poor outcome?

Dr Shin'oka. In the patients who underwent the RastelliSenning-type procedure, 33 of 69 patients had a VSD enlargement. Although I did not show the data, we compared LV function after surgery between the VSD-enlarged group and the nonenlarged group. The LV ejection fraction after surgery in the VSD enlarged group was $54.3 \%$, whereas the LV ejection fraction after surgery in the nonenlarged group was $53.2 \%$. We did not find any statistical difference between the groups.

Dr A. Corno (Liverpool, United Kingdom). You have used a long series of different surgical techniques, including, more or less, all the types of biventricular repair and the univentricular type of repair, but you have never used the one-and-a-half type of ventricular repair, consisting of arterial switch or Rastelli, the atrial rerouting limited to the inferior vena cava associated with bidirectional Glenn.

This option presents several advantages: (1) you have no risk of superior vena cava obstruction; (2) you increase the intra-atrial space available for the pulmonary venous return, therefore you reduce the risk of obstruction to the pulmonary venous return; (3) you reduce the intra-atrial suture lines, so you reduce the risk of arrhythmias; (4) you unload the right ventricle, and this is very useful when you have a relative hypoplasia or malfunction of the right ventricle; (5) you reduce the duration of the ischemic time; and (6) you also reduce the flow through the right ventricle to pulmonary artery connection.

My question is the following: in the patients from your study that are now considered, based on your experience, at higher risk, would you consider this option in the future?

Dr Shin'oka. Thank you, Dr Corno. Yes, I agree with the other option you recommended. We would like to try this option in the future either in conventional or anatomic repair when the patients have a relatively small-sized pulmonary ventricle.

Dr G. Stellin (Padova, Italy). You showed that the complete $\mathrm{AV}$ block is a frequent complication in repairing corrected transposition and especially when a VSD needs to be enlarged. You showed in your drawing that the incision is carried posteriorly, in the VSD. Do you use the same approach in IDD-corrected transposition?

Dr Shin'oka. Most patients with IDD also had an anterior conduction system in our series, and we performed the electrophysiologic studies before the operation. This study can determine 
the dominant AV node in almost all patients. Therefore, according to these findings, we can enlarge the VSD correctly.

Dr Stellin. According to the anatomist, the conduction system goes with a loop, so if you have an L loop, it's anterior. If you have a D loop, it's posterior. So if you have a large atrial septal defect in an IDD form or corrected transposition, you might indeed have injured your His bundle.

Dr Shin'oka. I do not agree with your opinion. It's not correct. There is a general agreement of an anterior conduction system in the situs solitus group, and a posterior conduction system was reported in the situs inversus group. However, we have observed many patients with an anterior conduction system in IDD, 16 of 21 patients. In addition, a dominant posterior conduction system was noticed even in an SLL heart, in 5 of 48 patients. Furthermore, a sling of conduction bundle was reported in cc-TGA in situs solitus with a straddling mitral valve. Therefore, the direction of the VSD enlargement should be carefully determined by means of the preoperative electrophysiologic study. 


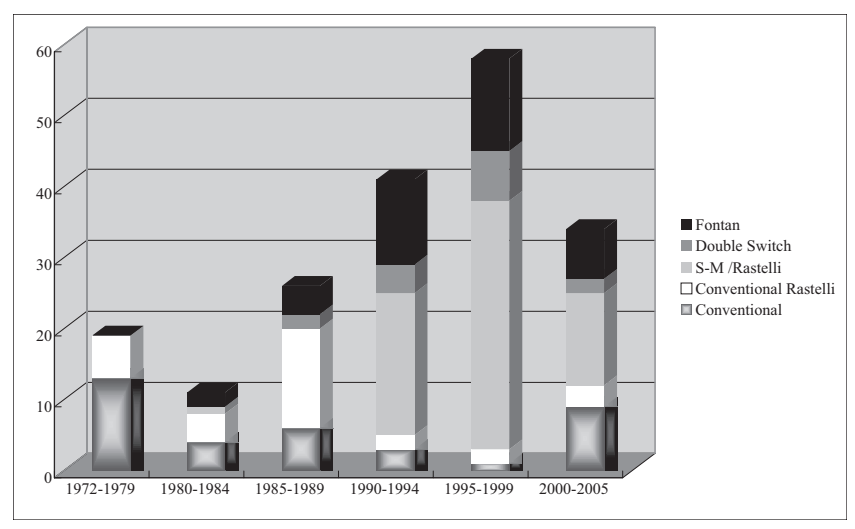

Figure E1. Number of patients over time depending on the surgical procedure. Double Switch, DSO (arterial and atria switch); $S-M / R a s t e l l i$, Senning or Mustard plus Rastelli procedure; Conventional, conventional repair (ASD or VSD closure \pm PS release, or isolated tricuspid valve surgery).

TABLE E1. Cause of hospital and late deaths

\begin{tabular}{lccc}
\hline & $\begin{array}{c}\text { Conventional repair } \\
(\mathbf{n}=\mathbf{6 7})\end{array}$ & $\begin{array}{c}\text { Anatomic repair } \\
(\mathbf{n}=\mathbf{8 4})\end{array}$ & $\begin{array}{c}\text { Fontan } \\
(\mathbf{n}=\mathbf{3 8})\end{array}$ \\
\hline LOS & 4 & 3 & 4 \\
CHF & 8 & 3 & 0 \\
Pulmonary hypertension & 0 & 1 & 0 \\
Infection & 2 & 3 & 1 \\
Arrhythmia/sudden death & 1 & 1 & 1 \\
Noncardiac & 1 & 1 & 0 \\
GI bleeding & 0 & 1 & 0 \\
Cerebral damage & 1 & 1 & 0 \\
Unknown & 1 & 1 & 1
\end{tabular}

LOS, Low-output syndrome; CHF, congestive heart failure; GI, gastrointestinal.

TABLE E2. Cause of reoperation

Conventional repair

(n = 67)

5

TVP/TVR

MVP

Conduit stenosis

SAS

Residual shunt

SVC stenosis

AVR

IE, pseudoaneurysm

Other
Anatomic repair

$(n=84)$

Fontan

(n = 38)

$T$ TVP, Tricuspid valvuloplasty; TVR, tricuspid valve replacement; $M V P$, mitral valvuloplasty; $S A S$, subaortic stenosis; $A V R$, aortic valve replacement; $I E$, infective endocarditis. 
Appendix E1. Predictors for Deaths

\begin{tabular}{|c|c|c|c|c|c|c|c|}
\hline \multicolumn{8}{|c|}{ All death: Cox proportional hazard model—univariable } \\
\hline \multirow[b]{2}{*}{ Variables } & \multirow[b]{2}{*}{ Factor numbers } & \multirow[b]{2}{*}{ Incidence } & \multicolumn{5}{|c|}{ Univariable } \\
\hline & & & $\boldsymbol{\beta}$ & SE & $P$ value & Odds ratio & $95 \% \mathrm{CI}$ \\
\hline Fontan & 38 & 7 & -0.247 & 0.412 & .55 & 0.78 & $0.35-1.75$ \\
\hline Conventional Rastelli & 31 & 7 & -0.313 & 0.418 & .45 & 0.73 & $0.32-1.66$ \\
\hline DSO & 15 & 3 & -0.118 & 0.599 & .84 & 0.89 & $0.27-2.87$ \\
\hline Female gender & 61 & 14 & -0.024 & 0.323 & .94 & 0.98 & $0.52-1.84$ \\
\hline Before year 1990 & 65 & 20 & 0.125 & 0.320 & .70 & 1.13 & $0.61-2.12$ \\
\hline Age $<3$ y & 22 & 8 & 0.581 & 0.390 & .14 & 1.79 & $0.83-3.84$ \\
\hline Weight $<10 \mathrm{~kg}$ & 18 & 8 & 0.729 & 0.392 & .06 & 2.07 & $0.96-4.47$ \\
\hline LTGA & 85 & 26 & 0.552 & 0.302 & .07 & 1.74 & $0.96-3.14$ \\
\hline Palliation & 121 & 28 & 0.025 & 0.310 & .94 & 1.03 & $0.56-1.88$ \\
\hline No use of conduit & 110 & 25 & -0.046 & 0.300 & .88 & 0.96 & $0.53-1.72$ \\
\hline VSD enlargement & 35 & 9 & 0.215 & 0.376 & .57 & 1.24 & $0.59-2.59$ \\
\hline Perfusion $\geq 240 \mathrm{~min}$ & 43 & 15 & 0.725 & 0.323 & .02 & 2.06 & $1.10-3.89$ \\
\hline Aortic clamp $\geq 120 \mathrm{~min}$ & 24 & 5 & -0.005 & 0.478 & .99 & 1.00 & $0.39-2.54$ \\
\hline CTR $\geq 60 \%$ & 29 & 8 & 0.293 & 0.398 & .46 & 1.34 & $0.61-2.92$ \\
\hline RVEDV $\geq 200$ & 18 & 4 & 0.184 & 0.539 & .73 & 1.20 & $0.42-3.46$ \\
\hline RVEF $<0.4$ & 4 & 1 & 0.540 & 1.019 & .60 & 1.72 & $0.23-12.64$ \\
\hline LVEDV $\geq 200$ & 19 & 4 & 0.085 & 0.540 & .87 & 1.09 & $0.38-3.14$ \\
\hline LVEF $<0.4$ & 4 & 2 & 1.314 & 0.736 & .07 & 3.72 & $0.88-15.75$ \\
\hline \multicolumn{8}{|c|}{ All death: Cox proportional hazard model—multivariable } \\
\hline & & & \multicolumn{5}{|c|}{ Multivariable } \\
\hline $\mathrm{TR} \geq 2$ & 40 & 16 & 0.899 & 0.471 & .06 & 2.46 & $0.98-6.19$ \\
\hline Perfusion $\geq 240 \mathrm{~min}$ & 43 & 15 & 0.690 & 0.422 & .10 & 1.99 & $0.87-4.56$ \\
\hline LVEF $<0.4$ & 4 & 2 & 1.039 & 0.804 & .20 & 2.83 & $0.58-13.67$ \\
\hline
\end{tabular}


Appendix E2. Predictors for Reoperation

\begin{tabular}{|c|c|c|c|c|c|c|c|}
\hline \multicolumn{8}{|c|}{ Reoperation: Cox proportional hazard model-univariable } \\
\hline \multirow[b]{2}{*}{ Variables } & \multirow[b]{2}{*}{ Factor numbers } & \multirow[b]{2}{*}{ Incidence } & \multicolumn{5}{|c|}{ Univariable } \\
\hline & & & $\boldsymbol{\beta}$ & SE & $P$ value & Odds ratio & $95 \% \mathrm{CI}$ \\
\hline Conventional & 36 & 8 & 0.555 & 0.453 & .22 & 1.74 & $0.72-4.23$ \\
\hline Fontan & 38 & 3 & -0.401 & 0.622 & .52 & 0.67 & $0.20-2.27$ \\
\hline Conventional Rastelli & 31 & 4 & -0.466 & 0.562 & .41 & 0.63 & $0.21-1.89$ \\
\hline DSO & 15 & 2 & 0.238 & 0.744 & .75 & 1.27 & $0.30-5.45$ \\
\hline Senning/Mustard-Rastelli & 69 & 7 & 0.014 & 0.471 & .98 & 1.01 & $0.40-2.55$ \\
\hline Female gender & 61 & 8 & 0.153 & 0.435 & .72 & 1.17 & $0.50-2.73$ \\
\hline Before year 1990 & 65 & 13 & 0.194 & 0.460 & .67 & 1.21 & $0.49-2.99$ \\
\hline Age $<3$ y & 22 & 5 & 0.863 & 0.506 & .09 & 2.37 & $0.88-6.39$ \\
\hline Weight $<10$ kg & 18 & 7 & 1.321 & 0.463 & .004 & 3.75 & $1.51-9.29$ \\
\hline LTGA & 85 & 13 & 0.322 & 0.415 & .44 & 1.38 & $0.61-3.11$ \\
\hline Palliation & 121 & 11 & -0.469 & 0.423 & .27 & 0.63 & $0.27-1.43$ \\
\hline LV only & 84 & 9 & 0.093 & 0.451 & .84 & 1.10 & $0.45-2.66$ \\
\hline RV only & 67 & 12 & 0.150 & 0.447 & .74 & 1.16 & $0.48-2.79$ \\
\hline $\mathrm{TR} \geq 2$ & 40 & 8 & 1.069 & 0.448 & .02 & 2.91 & $1.21-7.01$ \\
\hline No use of conduit & 110 & 15 & 0.261 & 0.423 & .54 & 1.30 & $0.57-2.97$ \\
\hline VSD enlargement & 35 & 6 & 0.735 & 0.489 & .13 & 2.09 & $0.80-5.44$ \\
\hline Perfusion $\geq 240 \mathrm{~min}$ & 43 & 4 & -0.234 & 0.552 & .67 & 0.79 & $0.27-2.33$ \\
\hline Aortic clamp $\geq 120 \mathrm{~min}$ & 24 & 5 & 0.763 & 0.509 & .13 & 2.14 & $0.79-5.82$ \\
\hline CTR $\geq 60 \%$ & 29 & 8 & 1.330 & 0.452 & .003 & 3.78 & $1.56-9.17$ \\
\hline RVEDV $\geq 200$ & 18 & 4 & 1.086 & 0.592 & .07 & 2.96 & $0.93-9.45$ \\
\hline RVEF $<0.4$ & 4 & 0 & & & & & \\
\hline LVEDV $\geq 200$ & 19 & 5 & 1.189 & 0.614 & .05 & 3.28 & $0.99-10.94$ \\
\hline LVEF $<0.4$ & 4 & 1 & 1.436 & 1.048 & .17 & 4.20 & $0.54-32.79$ \\
\hline \multicolumn{8}{|c|}{ Reoperation: Cox proportional hazard model-multivariable } \\
\hline & & & \multicolumn{5}{|c|}{ Multivariable } \\
\hline Variables & Factor numbers & Incidence & $\boldsymbol{\beta}$ & SE & $P$ value & Odds ratio & $95 \% \mathrm{CI}$ \\
\hline Female gender & 61 & 8 & -1.082 & 0.988 & .27 & 0.34 & $0.05-2.35$ \\
\hline Before year 1990 & 65 & 13 & 1.065 & 0.892 & .23 & 2.90 & $0.50-16.67$ \\
\hline Weight $<10 \mathrm{~kg}$ & 18 & 7 & 2.609 & 1.477 & .08 & 13.59 & $0.75-245.65$ \\
\hline LV only & 84 & 9 & -0.250 & 1.023 & .81 & 0.78 & $0.10-5.78$ \\
\hline VSD enlargement & 35 & 6 & 3.252 & 1.162 & .01 & 25.84 & $2.65-252.0$ \\
\hline $\begin{array}{l}\text { Aortic clamp } \geq 120 \\
\min \end{array}$ & 24 & 5 & 1.056 & 0.751 & .16 & 2.87 & $0.66-12.53$ \\
\hline CTR $\geq 60 \%$ & 29 & 8 & 2.137 & 0.748 & .004 & 8.47 & $1.96-36.71$ \\
\hline LVEDV $\geq 200$ & 19 & 5 & -0.109 & 1.156 & .93 & 0.90 & $0.09-8.64$ \\
\hline
\end{tabular}

Numbers in bold indicate statistical significance. $D S O$, double-switch operation; $L V$, left ventricular; $R V$, right ventricular; $T R$, tricuspid regurgitation; $V S D$, ventricular septal defect; CTR, cardiothoracic ratio; RVEDV, right ventricular end-diastolic volume; RVEF, right ventricular ejection fraction; $L V E D V$, left ventricular end-diastolic volume; $L V E F$, left ventricular ejection fraction. 
Appendix E3. Predictors for Pacemaker Implantation

\begin{tabular}{|c|c|c|c|c|c|c|c|}
\hline \multicolumn{8}{|c|}{ PM implantation: Cox proportional hazard model—univariable } \\
\hline \multirow[b]{2}{*}{ Variables } & \multirow[b]{2}{*}{ Factor numbers } & \multirow[b]{2}{*}{ Incidence } & \multicolumn{5}{|c|}{ Univariable } \\
\hline & & & $\boldsymbol{\beta}$ & SE & $P$ value & Odds ratio & $95 \% \mathrm{CI}$ \\
\hline Conventional & 36 & 1 & -1.302 & 1.032 & .21 & 0.27 & $0.04-2.06$ \\
\hline Fontan & 38 & 0 & & & & & \\
\hline Conventional Rastelli & 31 & 2 & -0.678 & 0.757 & .37 & 0.51 & $0.12-2.24$ \\
\hline DSO & 15 & 3 & 1.027 & 0.637 & .11 & 2.79 & $0.80-9.73$ \\
\hline Senning/Mustard-Rastelli & 69 & 11 & 1.302 & 0.513 & .01 & 3.68 & $1.35-10.05$ \\
\hline Female gender & 61 & 5 & -0.144 & 0.532 & .79 & 0.87 & $0.31-2.46$ \\
\hline Before year 1990 & 65 & 2 & -1.811 & 0.768 & .02 & 0.16 & $0.04-0.74$ \\
\hline Age $<3$ y & 22 & 6 & 1.756 & 0.512 & .001 & 5.79 & $2.12-15.79$ \\
\hline Weight $<10 \mathrm{~kg}$ & 18 & 3 & 0.973 & 0.637 & .13 & 2.65 & $0.76-9.22$ \\
\hline LTGA & 85 & 10 & 0.688 & 0.494 & .16 & 1.99 & $0.76-5.24$ \\
\hline Palliation & 121 & 12 & 0.377 & 0.534 & .48 & 1.46 & $0.51-4.15$ \\
\hline LV only & 84 & 12 & 1.947 & 0.642 & .002 & 7.01 & $1.99-24.66$ \\
\hline RV only & 67 & 3 & -1.129 & 0.642 & .08 & 0.32 & $0.09-1.14$ \\
\hline TR & 93 & 13 & 1.399 & 0.574 & .01 & 4.05 & $1.32-12.48$ \\
\hline $\mathrm{TR} \geq 2$ & 40 & 1 & -1.219 & 1.031 & .24 & 0.30 & $0.04-2.23$ \\
\hline No use of conduit & 110 & 7 & -0.573 & 0.493 & .25 & 0.56 & $0.21-1.48$ \\
\hline VSD enlargement & 35 & 11 & 2.267 & 0.512 & $<.0001$ & 9.65 & $3.54-26.33$ \\
\hline Perfusion $\geq 240 \mathrm{~min}$ & 43 & 5 & 0.524 & 0.540 & .33 & 1.69 & $0.59-4.87$ \\
\hline Aortic clamp $\geq 120 \mathrm{~min}$ & 24 & 2 & 0.063 & 0.756 & .93 & 1.07 & $0.24-4.69$ \\
\hline CTR $\geq 60 \%$ & 29 & 3 & 0.395 & 0.646 & .54 & 1.48 & $0.42-5.27$ \\
\hline RVEDV $\geq 200$ & 18 & 3 & 0.690 & 0.646 & .29 & 1.99 & $0.56-7.07$ \\
\hline RVEF $<0.4$ & 4 & 0 & & & & & \\
\hline LVEDV $\geq 200$ & 19 & 3 & 0.572 & 0.647 & 0.38 & 1.77 & $0.50-6.30$ \\
\hline LVEF $<0.4$ & 4 & 0 & & & & & \\
\hline \multicolumn{8}{|c|}{ PM implantation: Cox proportional hazard model-univariable } \\
\hline & & & \multicolumn{5}{|c|}{ Univariable } \\
\hline Variables & Factor numbers & Incidence & $\boldsymbol{\beta}$ & SE & $P$ value & Odds ratio & $95 \% \mathrm{Cl}$ \\
\hline Senning/Mustard-Rastelli & 69 & 11 & -1.890 & 1.277 & .14 & 0.15 & $0.01-1.85$ \\
\hline Female gender & 61 & 5 & -0.048 & 0.553 & .93 & 0.95 & $0.32-2.82$ \\
\hline Age $<3 y$ & 22 & 6 & 1.758 & 0.595 & .003 & 5.80 & $1.81-18.62$ \\
\hline LV only & 84 & 12 & 1.147 & 0.927 & .22 & 3.15 & $0.51-19.37$ \\
\hline $\mathrm{TR}$ & 93 & 13 & 0.808 & 0.637 & .20 & 2.24 & $0.64-7.82$ \\
\hline VSD enlargement & 35 & 11 & 3.355 & 1.118 & .003 & 28.65 & $3.20-256.28$ \\
\hline
\end{tabular}

Numbers in bold indicate statistical significance. $D S O$, double-switch operation; $L V$, left ventricular; $R V$, right ventricular; $T R$, tricuspid regurgitation; $V S D$, ventricular septal defect; CTR, cardiothoracic ratio; RVEDV, right ventricular end-diastolic volume; RVEF, right ventricular ejection fraction; $L V E D V$, left ventricular end-diastolic volume; $L V E F$, left ventricular ejection fraction. 